\title{
Revista de la
}

CEPAL

Director

RAUL PREBISCH

Secretario Térnico

ADOLFO GURRIERI

Secretaria Adjunta

ROSA NIELSEN

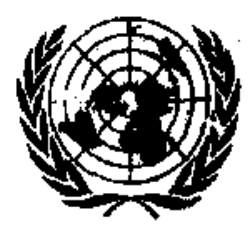

NACIONES UNIDAS

COMISION ECONOMICA PARA AMERICA LATINA Y EL CARIBE

SANTIAGO DE CHILE, DICIEMBRE DE 1984 
Revista de la

C E P A L

Santiago de Chile

Número 24

\section{SUMARIO}

La absorción productiva de la fuerza de trabajo: una polémica abierta. Centro de Proyecciones Económicas de la CEPA.

Metropolización y terciarización: malformaciones estructurales en el desarrollo latinoamericano. Anibal Pinto

Pobreza y subempleo en América Latina. Albento Couricl

Urbanización y mercado de trabajo. Joseph Ramos

Las transformaciones sectoriales del empleo en América Latina. Rubén Kaztman

Transformación ocupacional y crisis. Norberto Garia y Victor Tokman

103

Uso social del excedente, acumulación, distribución y empleo. Armando Di Filippo

El escenario internacional y la deuda externa de América Latina. Luciano Tomassini

La crisis financiera internacional: diagnosis y prescripciones. Martine Guerguil

Comentarios de libros

Jorge Daly: The political economy of detahation: the case of Peru 1975-1978 (Robert Devlin)

Autoafirmación colectiva: una estrategia alternativa de desarrollo.

Selección de Enrique Oteiza (Marshall Wolfe)

Lista de publicaciones de la CGPAL 
REVISTA DE LA CEPAL $\mathbf{N}^{\circ} 24$

\section{Urbanización y mercado de trabajo}

\author{
Joseph Ramos*
}

Como es sabido, en el perioklo de posguerria, América Latina vivió un proceso de crecimiento demogrático y urbanización sin precedentes en su historia. En 1950 1980 su poblaciôn tostal se duplicó con creces y su población urbana aumentó a más del triple, a purto tal que el simple increntento de la población urbana en esos treinta años fue casi idéntion al total de población que habia en el continente en 1950.

Este artículo examina como se absonlsio ente acelerado crecimiento denografico en el mercalo de trabajo, sobre todo cuando se volco hacia las ciudades, A juicio del atuor, este incremento de la oferta de trabajo encontro salida por efecto de un anmento concomitante en la demanda, creandose empleo productivo gracias al acelerado crecimiento econónico de la región durante las últimas décadas.

Desde 1980, America Latina ha sufriclo una crisis econónica aguda que invierte esta tendencia, confirmando cuán setsibte es la situación del empleo al creciniento económico. Por ello, concliye que un crecinienu concentrador y heterogéneo como el de 1950-1980 plantea problemas, pero muchos menos que los que ha traido consigo un retroceso económico como el de los áltimos años.

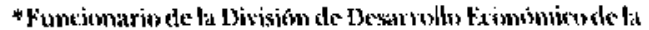
(A: I'AI.

\section{I \\ Modelos de urbanización y empleo}

A la luz de modelos explicativos del proceso de urbanización, se examinará en qué medida la urbanización fue saludable, en el sentido de obedecer a una mayor demanda de trabajo, os si fue malsana, excesiva o prematura, al responder más bien a las presiones de una sobreoferta de mano de obra.

\section{La expulsión rural: oferta dinámica y demanda estancada}

Según este análisis formulado primeramente por la cEPAl, los problemas de creciente sobreurbanización y subempleo en el periodo de postguerra surgieron del impacto del acelerado crecimiento demográfico sobre los sectores con exigua capacidad de absorción: el agropecuario y el industrial. La capacidad de absorción de la agricultura estaba limitada por una estructura concentrada de la propiedad, que dejaba buena parte de la tierra subaprovechada y obligaba al grueso de la fuerza de trabajo rural a subocuparse en actividades marginalmente productivas en la escasa tierra restante, Con tal subocupación, al sobrevenir la explosión demográfica de posguerra, se aceleró la urbanización, pues el campo ofrecía limitadas oportunidades de trabajo.

A su vez, se arguía que la tecnología moderna industrial -en general intensiva en su uso de maquinaria y ahorradora de mano de obratenia insuficiente flexibilidad para ajustarse a una oferta creciente de fuerza trabajadora; su capacidad de absorción se veía limitada más bien por las exigencias tecnológicas y el nivel de la producción. Al irrumpir en las ciudades esta mayor oferta se enfrentó con un sector industrial incapaz, por razones tecnológicas, de ampliar significativamente su absorción de mano de obra. En consecuencia, esta mano de obra urbana se volcó hacia actividades marginales y de fácil acceso en el sector terciario o en el sector informal secundario. Asi pues, el período de postguerra se caracterizó por una urbanización prematu$\mathrm{ra}$, no justificada por el lenco crecimiento del empleo fabril secundario, y por una terciarización e informalización excesiva con el subempleo resultante. "La gravedad del crecimiento urbano 
latinoamericano (se debe a) que marcha delante del desarrollo económico y que obedece a impulsos y fuerzas sociales autónomos. ...Como las oportunidades de encontrar empleo en los sectores de elevada productividad eran escasas, la fuerza de trabajo se vio forzada a desplazarse hacia ocupaciones poco productivas y escasamente remuneradas" (CEPAL, 1965).

\section{Un señuelo: la ciudad sirena}

Según esta tesis, elaborada primeramente por Harris y Todaro (1970), la migración resulta de la atracción de salarios urbanos artificialmente altos (de ahí lo de ciudad sirena). Estos son altos, se alega, por el efecto conjunto de políticas de exagerados reajustes legales y salarios mínimos, presiones sindicales y escalas de sueldos abultadas para el sector público. Por la aparente diferencia de remuneraciones, se genera un exceso de migración. Aunque no todos encuentran empleo, migran hasta hacer equivalentes los niveles esperados de ingreso en las zonas rurales y urbanas. Por un prisma más realista, como existe la alternativa de trabajar en actividades de fácil acceso con salarios flexibles (el sector desprotegido o informal), migran hasta hacer equivalente el ingreso esperado en las zonas rurales y urbanas (este último es igual a la probabilidad de conseguir un salario alto en el sector formal más la probabilidad mayor de recibir un salario informal más bajo o estar desempleado) (Piñera y Selowsky, 1976 y 1978, y Fields, 1975). De tal manera, no es el salario lo que equilibra el mercado de trabajo y regula las corrientes migratorias sino el desempleo urbano y los aumentos del empleo en actividades terciarias o informales de escasa productividad y que sirven para absorber, o, más bien dicho, disfrazar el desempleo. En consecuencia, la migración, atraída por salarios artificialmente altos, reduce la producción agropecuaria sin elevar la urbana (variante de Harris y Todaro, sobre el incremento del desempleo) o elevando la producción urbana en menos de lo que reduce la agropecuaria (variante de Fields, sobre aumento del empleo informal).

\section{Atracción genuina: la industrialización exige empleo terciario}

Según este criterio, primeramente expuesto por Galenson (1963), la industrialización moderna requiere mucho menos mano de obra por unidad de producto que en el siglo XIX, pero necesita una más calificrida que antes. Por eso crecerá poco el empleo industrial, sobre todo el de baja calificación. Sin embargo, sostiene que el empleo terciario es función, no del empleo secundario, sino del producto secundario. Pese a que, por razones tecnológicas, la industrialización de posguerra no se traduzca en tan importantes aumentos del empleo industrial como en el siglo xix, generará una demanda genuina de mano de obra por parte de actividades terciarias. El empleo terciario es una especie de demanda derivada del producto y productividad del sector industrial y por ello se observará una creciente urbanización a mayor producción industrial, en que tendrá un peso cada vez más importante el empleo terciario, siendo bastante inferior la generación de empleos por el secundario.

\section{Hechos e interpretaciones}

\section{Visión global}

En la evolución del empleo en América Latina entre 1950 y 1980 se advierten tres hechos sobresalientes: ${ }^{1}$

\footnotetext{
'Aunque parezca mentira, debido a la lentilud con que se elaboran los censos, no disponemos de datos censales sobre
}

\begin{abstract}
fuerza de trabajo para 1980 para casi ningún país de la región. De ahi que, en este trabajo, casi todas las cifras para 1980 se basen en las estimaciones realizadas por PREAL: a base de las tendencias censales de 1950-1970 junto con la evolución posterior de la fuerza de trabajo según censos ocupacionales en el decenio de 1970 (PkF:A1, , 1982). Estos datos (porcentajes) de prEalc; se han aplicado a kas estimaciones de población en edad de trabajar de chiabr: (1983).
\end{abstract}


a) Se absorbió la explosión demográfica y la aceleración en la urbanización de postguerra sin que se elevara la tasa de desempleo. La ocupación total creció a un ritmo de $2.5 \%$ anual, subiendo a más del doble en el periodo." ${ }^{2}$ La ocupación urbana creció a un ritmo de $3.8 \%$ anual (se triplicó holgadamente en el periodo).

b) Hubo una recomposición sectorial masiva de la fuerza de trabajo desde el sector primario ${ }^{3}$, que cayó de $56 \%$ de la población económicamente activa (PKA) en 1950 a $36 \%$ en 1980 , con una expansión concomitante de las actividades tanto del sector secundario como del terciario. Aunque el empleo terciario tendio a crecer más que el secundario, todo el período se caracterizó por la relativa estabilidad en la proporción de la fuerza de trabajo urbana ocupada en el sector secundario $(40 \%)$ y terciario $(60 \%)$.

c) Más importante aún que los cambios en la composición sectorial de la fuerza de trabajo fueron las notables mejoras en la productividad de la fuerza de trabajo dentro de cada sector (producto sectorial $\div$ YEA sectorial). Esta subió a más del doble en los treinta años tanto en el sector primario como el secundario, mientras se elevaba en $70 \%$ en el sector terciario.

Se pueden apreciar mejor los avances en el período de postguerra si se comparan las cifras con el lapso 1925-1955 (cuadro 1). Se aceleró el crecimiento demográfico de $2.2 \%(1925-1955)$ a $2.7 \%$ anual (1950-1980); disminuyó la absorción de empleo por el sector primario ( $1.4 \%$ a $1.0 \%$ anual), pero la proporción de la PEA en el sector primario cayó sólo 20 puntos porcentuales en

\footnotetext{
${ }^{2}$ Salvo indicación en contrario, los datos sobre fiterza cle trabajo y producto urbano y su evolución se refieren a la fuerza de trabajo no agrícola y no minera, es decir, la fuerza de trabajo secundaria y terciaria o su producción. Esa aproximacion, aunque no es ideat, es necesaria para estimar 1980, pues la información disponible no esta desylosada según sea urbana y rural. No obstante, considero probable que la evolucón de la fuerza de trabajo urbana sea sinilar a la secundaria más terciaria, ya que esias últimas constituyen el grueso de la fuerza de trabajo urbana.

"Las definiciones son las siguientes: sector primario= agricultura, pesca, silvicultura y minería: sector securdario=manufactura, construcción, electricidad, gas y agua; sector terciório=transporte y comunicaciones, comercio y finanzas, administración pública y defensa, servicios, otros.

${ }^{4}$ Por falta de intormación, me refiero a $1925-1955$ y noa 1920-1950.
}

1950-1980 en lugar de 10 en 1925-1955. De ahí que se apremió a las actividades urbanas para generar empleo. Estas respondieron bien: el empleo terciario creció a una tasa que subió de $3.3 \%$ a $3.9 \%$ anual, y la del empleo secundario de $2.2 \%$ a $3.7 \%$ anual. Aunque aumentó la participación de ambos sectores en la PEA, el cambio más notable se dio en el comportamiento de la PEA manufacturera: su participación subió en poco más de $1 / 2$ punto porcentual en 1925-1955 y en más de 4 entre 1950 y 1980.

Todo esto se logró sin reducir el ritmo de crecimiento de la productividad. Por el contrario, ascendió aceleradamente tanto en el sector primario (1.2\% a $2.6 \%$ anual) como en el terciario $(0.4 \%$ a $1.8 \%$ anual $)$. La productividad del sector secundario mantuvo un fuerte ritmo de crecimiento.

A primera vista y sin entrar en detalles por países, parecería que eran infundados los temores de que la explosión demográfica y la aceleración del proceso de urbanización de postguerra pudieran dar lugar a una crisis de empleo. Los tres sectores tuvieron una dinámica evolución tanto del empleo como de la productividad. Aunque el empleo terciario se elevó poco más que el del secundario y su productividad en menor proporción, mejoró notablemente su capacidad de absorción y su productividad en comparación con los niveles de 30 años antes. De ahí que pese a la desaceleración del empleo primario, subieran tanto el ritmo de absorción de empleo en la economía en su conjunto $(2.0 \%$ a $2.5 \%$ anual) como el de la productividad gkbal ( $1.6 \%$ a $3.0 \%$ anual).

De no haber habido tal evolución en la postguerra la situación habría sido muy distinta. Sin la mayor demanda de trabajo que resultó de la acrecentada producción, no habría sido fácil absorber los mayores incrementos en la oferta de trabajo sin merma de su productividad ${ }^{5}$. En cam-

\footnotetext{
"Por qué se aceleró la producción en el período de postguerra - difusión masiva de la educación, profesionalización de las élites empresariales y burocráticas, industrialización, mayor ahorto e inversión, aprovechamiento de la tecnologia moderna y de las ventajas de un desarrollo tardio, un medio externo favorable, etc.-, es materia de otro trabajo. Baste aqui señalar el hecho que ese acelerado crecimiento económico redundó en una mayor demanda de trabajo, en grado suficiente como para compensar el acelerado ritmo de crecimiento demográfico y urbano.
} 
Cuadro 1

EVOLUCION DE LA POBLACION, EMPLEO, PRODUCTO Y PRODUCTIVIDAD SECTORIAL 1925-1980

(Tasas anuales de crecimiento)

\begin{tabular}{|c|c|c|c|c|c|c|}
\hline \multirow{2}{*}{ Totales } & \multicolumn{3}{|c|}{$1925-1955$} & \multicolumn{3}{|c|}{$1950-1980$} \\
\hline & \multirow{2}{*}{\multicolumn{3}{|c|}{$2.2 \%$}} & \multirow{2}{*}{\multicolumn{2}{|c|}{$2.7 \%$}} & \\
\hline Población & & & & & & \\
\hline Población urbana & \multicolumn{3}{|c|}{3.5} & \multicolumn{3}{|c|}{4.1} \\
\hline PEA total & \multicolumn{3}{|c|}{2.0} & \multicolumn{3}{|c|}{2.5} \\
\hline PEA "urbana" ה & \multicolumn{3}{|c|}{2.9} & \multicolumn{3}{|c|}{3.8} \\
\hline PEA "rural"rtr & \multicolumn{3}{|c|}{1.4} & \multicolumn{3}{|c|}{1.0} \\
\hline \multicolumn{7}{|l|}{ Distribuctón de PEA } \\
\hline Ptimario & $62.3 \%$ & & $51.1 \%$ & $56.2 \%$ & & $35.9 \%$ \\
\hline Manufacturero & 13.7 & & 14.3 & 14.1 & & 18.3 \\
\hline \multirow[t]{4}{*}{ Demás sectores } & 24.0 & & 34.6 & 29.7 & & 45.8 \\
\hline & \multicolumn{6}{|c|}{ Crecimiento anual del productn, pes y productividad } \\
\hline & \multicolumn{3}{|c|}{$1925-1955$} & \multicolumn{3}{|c|}{$1950-1980$} \\
\hline & $P I B$ & PEA & Productividad & $P I B$ & PEA & Productividad \\
\hline Total de economía & $3.7 \%$ & $2.0 \%$ & $1.6 \%$ & $5.5 \%$ & $2.5 \%$ & $3.0 \%$ \\
\hline Agricultura & 2.7 & 1.4 & 1.3 & 3.5 & 1.0 & 2.5 \\
\hline Primaria & 2.6 & 1.4 & 1.2 & 3.6 & 1.0 & 2.6 \\
\hline Secundariac & 4.9 & 2.2 & 2.7 & 6.5 & 3.7 & 2.7 \\
\hline Terciariad & 3.7 & 3.3 & 0.4 & 5.7 & 3.9 & 1.8 \\
\hline "Urbana" & 4.0 & 3.0 & 1.0 & 6.0 & 3.8 & 2.1 \\
\hline
\end{tabular}

Fuente: CEPAL, 1965 y 1978: PREALC, 1982.

División de Estadística de la CEPAl. cifras inéditas de estimación del producto para 1980. La evolución de la PEA y la población en 1950-1980 se tomaron de los cuadros siguientes.

aLa PEA urbana se calcula como la PEA no agricola y no minera.

bLa PEA rural se calcula como la PEA agrícola y minera.

'Para 1925-1955 se toma como la evolución del PLS y la PEA manufactureros.

"Para 1925-1955 se toma como la evolución del PtB y la PEA no primarios, ni manufactureros.

bio, fue posible elevar tanto la generación de empleos como su productividad, o al menos ésta es la hipótesis que surge de un examen preliminar de las estadísticas globales a nivel regional.

¿No será posible que, aun con el fuerte crecimiento del producto, la demanda de trabajo haya crecido más lentamente que la oferta, de modo tal que el empleo urbano generado haya sido subempleo más bien que empleo productivo? Es decir, ¿no es posible que el mayor volumen de empleo y la más alta productividad media sectorial reflejen una combinación de a) lento crecimiento en el empleo, pero rápida elevación de la productividad en actividades formales con tecnología moderna y b) acelerada expansión del empleo en actividades de baja productividad del sector informal y terciario?

\section{El análisis detallado}

Sólo el examen detallado (por período y país) permitirá aclarar en qué medida esta evolución, aparentemente positiva, del empleo se debe a una aceleración en el ritmo de crecimiento económico o a una creciente heterogeneidad en la producción y mayor segmentación del mercado 
de trabajo $\longrightarrow$ sea, se deba a una expansión del empleo generada por la demanda o por la oferta (el sector informal).

\section{a) Total de empleos generados}

En general, la población alcanzó su máximo crecimiento en la región en los decenios de 1950 y 1960 (2.8\% frente al 2.2\% anual de $1925-1955$ ) para luego decaer en los años del setenta. Como demora de doce a quince años antes que esos nuevos contingentes lleguen a la edad de trabajar, el periodo 1960-1980 fue el más difícil en cuanto a la necesidad de absorber mano de obra (cuadro 2).

Cuadro 2

CRECIMIENTO DE LA POBLACION, DE LA POBLACION EN EDAD DE TRABAJAR, Y DE LA PEA POR DECENIO, 1950-1980

(Tasas de crecimienta anual)

\begin{tabular}{lcccc}
\hline & $1950-1960$ & $1960-1970$ & $1970-1980$ & $1950-1980$ \\
\hline Población & 2.8 & 2.8 & 2.5 & 2.7 \\
PEA & 2.1 & 2.5 & 3.0 & 2.5 \\
Población en edad & & & & \\
$\quad$ de trabajar & 2.6 & 2.9 & 2.9 & 2.8 \\
Población urbana & 4.4 & 4.3 & 3.5 & 4.1 \\
PEA urbana & 3.6 & 3.6 & 4.2 & 3.8 \\
\hline
\end{tabular}

Ftente: CEPAL, 198I; y CELADE, 1983.

La evolución de la PEA urbana equivale a la de Ja PE.A no agrícola y no minera.

Vale la pena detenerse en dos hechos (cuadro 2). Por vez primera, en el decenio de 19701980, la PEA creció con rapidez mayor que la población, tanto en localidades urbanas como en cada pais en su conjunto. Por su parte, como los datos ('PREAL.c., 1982, cuadro II-1) indican que el desempleo abierto no empeoró en el perfodo, aparentemente no se habría elevado la proporción entre ocupados (o aportantes de ingreso) e inactivos y desocupados en cada familia, y, por lo tanto, el ingreso familiar habria subido más rapidamente que el ingreso per cápita.

Por otro lado, y de nuevo por vez primera, en 1970-1980 la fuerza de trabajo (y la ocupación) crecieron con rapidez mayor que la poblacion en edad de trabajar, pese a que esta última había llegado a su ritmo máximo. Esto se debió a que las tasas de participación en las edades postescolares (mayores de 20 años) tendieron a estabilizarse para los hombres y a subir para las mujeres. El que esas tasas de participación se hayan elevado sin que el desempleo abierto haya aumentado abona la hipótesis de que el empleo se generó más bien por una mayor demanda de trabajo que por una mayor oferta (a no ser que la productividad del trabajo o los salarios reales o ambos a la vez, hubieran decaido - cosa que, como veremos en seguida, no sucedió).

\section{b) Crecimiento del empleo urbano}

i) i Urbanización sin industrialización? Si bien es cierto que el proceso de urbanización se aceleró en 1950-1980, sobre todo en el decenio de 1970 , no lo es menos que evolución igualmente dinámica registraron tanto el producto urbano como el del sector secundario, lo que sugiere que el crecimiento de la fuerza de trabajo urbana obedeció más bien al impulso de una mayor demanda de trabajo que al de una mayor oferta.

Para profundizar en este punto, se examinó la relación entre el incremento del producto urbano (secundario y terciario), como indicador indirecto (proxy) de la demanda de empleo pro- 


\section{Gráfico I}

RELACIONES ENTRE EL CRECIMIENTO DEL PRODUCTO Y EL CRECIMIENTO DEL EMPLEO
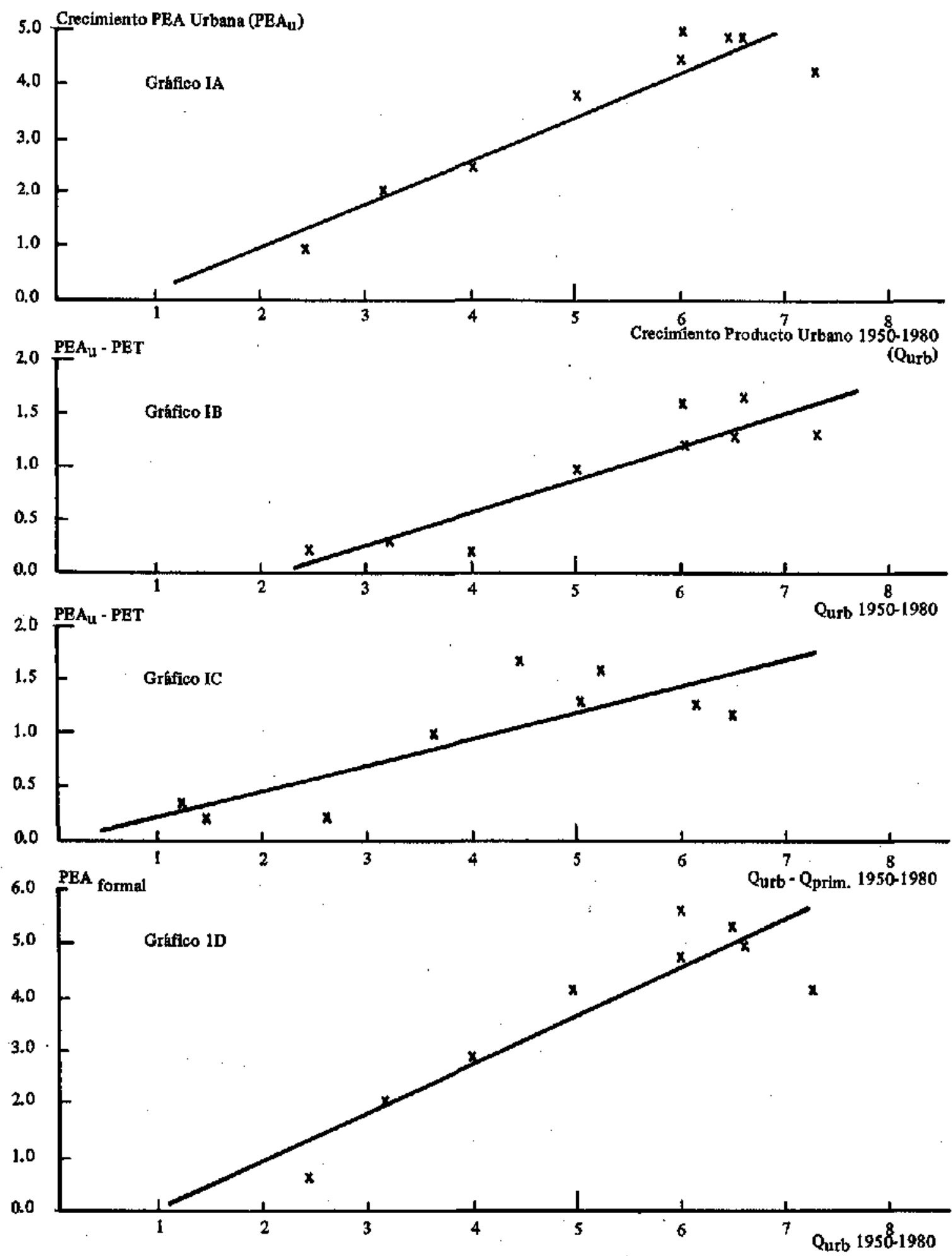
ductivo urbano, y el crecimiento de la fuerza de trabajo urbana entre 1950 y 1980 para los nueve países de mayor producto y empleo en la región (gráfico IA). ${ }^{6} Q$ ue esta relación resultara positiva implica que la urbanización en estos treinta años obedeció a una demanda de empleo creciente más bien que a una mayor oferta de trabajo.

Para controlar el hecho de que la fuerza de trabajo urbana se elevara más rápidamente - sin mayor urbanización - en la medida que sea mayor el ritmo de crecimiento demográfico, se relacionó la diferencia entre los ritmos de crecimiento de la PEA urbana y de la población en edad de trabajar con el crecimiento del producto urbano para los mismos años 1950-1980 (gráfico IB). Una vez más la relación fue positiva, significativa y muy marcada. ${ }^{7}$

Por último, para controlar el hecho de que la urbanización puede ser función más bien del mayor crecimiento del producto urbano que del primario, se relacionó la diferencia entre los ritmos de crecimiento de la PEA urbana y de la población en edad de trabajar con la diferencia entre los ritmos de crecimiento del producto urbano y del producto primario (gráfico IC), relación que también fue positiva, significativa y muy marcada. $^{8}$

\section{Urbanización e informalización}

No obstante lo anterior ¿no sería posible que el producto urbano hubiera crecido sin que hubiera aumentado en igual proporción el empleo

"La regresión simple entre estas variables fue: el ritmo" de crecimiento del empleo urbano $=0.7+(0.83)$ (el ritmo de crecimiento del producto urbano) $, \mathrm{R}^{2}=94 \%, \mathrm{t}=7.3$. Por el reducido número de las observaciones no ha de prestarse mucha importancia a la magnilud de los coeficientes. Lo importante es reconocer que sí hay una relación —al menos es mucho más probable que ta afirmación contraria, cual es de que hubo sobreurbanización. Esto vale para ésta y las demás regresiones de este trabajo.

${ }^{7}$ La tegresión simple fue: la diferencia entre los ritmos de crecimiento del empleo urbano y de la población en edad de trabajar $=-0.7+(0.32)$ (el ritmo de crecimiento del producto urbano), $\mathrm{R}=90 \% ; \mathrm{t}=\mathbf{5 . 6}$.

"La regresión simple fue: la diferencia entre los rimos de crecimiento del emples, urbano y de la población en edad de trabajar $=-0.04+(0.5)$ (la diferencia entre los rituos de crecimiento del producto urbano y del primario), $\mathbf{R}^{2}=82 \%$, $\mathbf{t}=\mathbf{\$} .9$. productivo urbano, por efecto de una mayor heterogeneidad de la producción? Es decir, ¿no. sería posible que la producción urbana se hubiera expandido porque crecieron las actividades modernas pero que no hubiera aumentado el empleo moderno de la misma forma porque su productividad se elevó notablemente? De ser así, el empleo generado habría correspondido a actividades de baja productividad y fácil acceso, o sea, al sector informal, donde el empleo se ajusta a la oferta, y no a actividades formales, claro indicio de una mayor demanda de empleo productivo.

A base de las estimaciones de pkeslc: sobre la evolución del empleo formal ${ }^{\text {entre }} 1950$ y 1980 se observa que:

-El crecimiento del empleo formal fue muy superior al de la población en edad de trabajar en la región en su conjunto en todo el periodo y en cada uno de los tres decenios (cuadro 3). Además al considerarlos en detalle casi no se observan excepciones entre los nueve paises considerados. La única es el Uruguay, país en que el empleo formal crece a un ritmo ligeramente inferior que la población en edad de trabajar, pero-lo que es muy sugestivo- es el pais de menor crecimiento del producto urbano en el período.

-El empleo formal tendió a aumentar a un ritmo igual o un poco superior al del empleo urbano en la región en su conjunto y en siete de los nueve países examinados; las excepciones son Uruguay y la Argentina, los dos de menor crecimiento del producto urbano en la región. (Véase la relación PEA formal a PEA urbana entre 1950 y 1980 en el cuadro 4.)

- Comprobaciones más fragmentarias para seis países ${ }^{10}$ sugieren que en el sector secundario el empleo formal creció a un rítmo anual (4.1\%) superior al del sector informal $(2.9 \%)$, y al de la fuerza de trabajo total $(2.5 \%)$ y urbana $(3.8 \%)$.

Como 70\% del empleo urbano suele estar en el sector formal por lo menos $70 \%$ del nuevo

\footnotetext{
"Para estas estimaciones PREAlc consideró como empleo formal el trabajo asalariado urbano, salvo el empleo doméstico y el empleo por cuenta propia de profesionales y técnicos. O sea, el sector informal está constituido por los trabajadores por cuenta propia y los familiares no remunerados, salvo los profesionales y técnicos.

"Brasil, Costa Rica, Chile, Panamá, Perú y Venezuela (Kaztrnan, 1983).
} 
Cuadro 3

CRECIMIENTO RELATIVO DEL EMPLEO FORMAL

(Tasas de crecimierio anual)

\begin{tabular}{|c|c|c|c|c|}
\hline & $1950-1960$ & $1960-1970$ & $1970-1980$ & $1950-1980$ \\
\hline $\begin{array}{l}\text { Población } \\
\text { econónicamente activa } \\
\text { Población en edad de }\end{array}$ & $2.1 \%$ & $2.5 \%$ & $3,0 \%$ & $2.5 \%$ \\
\hline trabajar (PET) & 2.6 & 2.9 & 2.9 & 2.8 \\
\hline Población urbana & 3.6 & 3.6 & 4.2 & 3.8 \\
\hline Empleo formal & 3.6 & 3.8 & 4.1 & 3.9 \\
\hline \multicolumn{5}{|l|}{$\begin{array}{l}\text { Pablación en edad de } \\
\text { trabajar }\end{array}$} \\
\hline Argentina & 1.9 & 1.7 & 1.5 & 1.7 \\
\hline Brasil & 2.9 & 3.1 & 2.9 & 3.0 \\
\hline Colombia & 2.6 & 3.2 & 3.0 & 2.9 \\
\hline Costa Rica & 3.2 & 3.9 & 3.7 & 3.6 \\
\hline Chile & 2.2 & 2.4 & 2.3 & 2.3 \\
\hline Méxjco & 2.7 & 3.3 & 3.4 & 3.1 \\
\hline Perú & 2.2 & 2.7 & 3.1 & 2.8 \\
\hline Uruguay & 1.2 & 1.1 & 0.4 & 0.9 \\
\hline Venezuela & 3.4 & 4,0 & 4.1 & 3.8 \\
\hline \multicolumn{5}{|l|}{ Emples formal } \\
\hline Argentina & 2.7 & 1.7 & 1.3 & 1.9 \\
\hline Brasil & 3.7 & 4.8 & 4.5 & 4.3 \\
\hline Colombia & 3.6 & 6.4 & 4.2 & 4.7 \\
\hline Costa Rica & 4.5 & 5.8 & 6.0 & 5.4 \\
\hline Chile & 2.3 & 3.2 & 2.8 & 2.8 \\
\hline México & 6.5 & 3.3 & 5.2 & $5.1)$ \\
\hline Perú & 3.4 & 4.2 & 4.6 & 4.1 \\
\hline Uruguay & 1.3 & 1.2 & 0.1 & 0.9 \\
\hline Venezueia & 5.3 & $\$ .4$ & 7.0 & 5.6 \\
\hline
\end{tabular}

Fuente: PREALC, 1982; CEPAL, 1981; GFLAJ), 1983.

Cuadro 4

EMPLEO FORMAL EN RELACION CON LA PEA TOTAL Y LA PEA URBANA, 1950-1980)

\begin{tabular}{|c|c|c|c|c|c|c|c|c|}
\hline & \multicolumn{3}{|c|}{ PEA formal } & \multirow[b]{3}{*}{1980} & \multirow{2}{*}{\multicolumn{3}{|c|}{$\begin{array}{l}\text { PEA formal } \\
\text { PEA urbana }\end{array}$}} & \multirow[b]{3}{*}{1980} \\
\hline & \multicolumn{3}{|c|}{ PEA total } & & & & & \\
\hline & 1950 & 1960 & 1970 & & 1950 & 1960 & 1970 & \\
\hline Toda la region & $30.1 \%$ & $94.9 \%$ & $39.8 \%$ & $44.6 \%$ & $69.2 \%$ & $69.1 \%$ & $70.2 \%$ & $69.7 \%$ \\
\hline Argentina & 56.8 & 68.4 & 66.0 & 65.0 & 78.9 & 81.7 & 80.9 & 77.0 \\
\hline Brasi] & 28.5 & 31.8 & 38.6 & 45.2 & 72.7 & 67.4 & 72.1 & 72.8 \\
\hline Colombia & 23.9 & 28.0 & 38.7 & 42.6 & 61,0 & 62.1 & 68.6 & 65.6 \\
\hline Costa Rica & 29.7 & 35.1 & 44.1 & 52.9 & 70.7 & 73.4 & 77.4 & 81.0 \\
\hline Chile & 40.8 & 44.5 & 53.1 & 54.1 & 64.9 & 68.5 & 76.1 & 72.9 \\
\hline México & 21.6 & 32.2 & 33.9 & 39.5 & 62.6 & 70.5 & 65.1 & 64.2 \\
\hline Perú & 19.1 & 23.7 & 29.8 & 35.0 & 53.1 & 57.0 & 59.0 & 59.5 \\
\hline Uruguay & 63.3 & 63.6 & 64.2 & 63.3 & 81.4 & 80.3 & 79.3 & 76.9 \\
\hline Venezuela & 34.7 & 48.1 & 48.9 & 62.6 & 67.9 & 68.3 & 68.6 & 79.2 \\
\hline
\end{tabular}

Fuente: PREALC, 1982

"La PEA urbana equivale a la PEA no agrícola y no minera. 
empleo generado en el sector habría correspondido a la demanda de trabajo productivo (actividad formal) y no a la oferta. Por eso es que al relacionar el crecimiento del empleo formal con el crecimiento del producto urbano (gráfico ID), se advierte una fuerte relación positiva, casi idéntica a la que se da al comparar el crecimiento de todo el empleo urbano con el producto urbano (gráfico IA). ${ }^{11}$

Además, aunque el sector informal se presta a cumplit una función absorbente frente a un exceso de oferta de trabajo, esto no significa que el empleo informal se genere sólo o principalmente por presiones de la oferta. De ser asi, su productividad y salario decaerían (cosa que no parece haber ocurrido). En efecto llaman la atención (cuadro 4) tanto la escasa variación en la alta proporción de la fuerza de trabajo urbana del sector formal en países de muy distinto nivel de desarrollo $(70 \% \pm 10 \%)$ como su constancia relativa en el tiempo tanto en paises de desarrollo económico rápido (Brasil) como lento (Argentina). Esto sugiere que buena parte del empleo informal es una demanda derivada de la actividad formal -ocupando espacios complementarios (García, 1979, cap. 1). De ahí la relativa estabilidad en la relación entre ésta y el empleo formal. Así pues, la expansión del empleo informal podria representar impulsos de demanda más bien que de oferta. En ese caso, por supuesto, su productividad se elevaría, al revés de lo que ocurriría si sólo actuara como absorbente.

\section{3. ¿Sobreterciarizacion?}

En algunos casos el subempleo se manifiesta no tanto en la proliferación de actividades informales, cuanto en la sobrexpansión del sector terciario. Como este sector reúne actividades de muy variada indole y productividad -la banca y el comercio al por mayor; el comercio ambulante y

\footnotetext{
"La regresión simple es: el ritmo de creciniento del empleo formal $=-0.9+(0.91)$ (el crecimiento del producto urbano). $\mathbf{R}^{2}=\mathbf{9 1 \%}, \mathrm{t}=\mathbf{5 . 7}$. La misna relación con el empleo urbano daba un coeficiente de regresión de 0.83 , y uno constante de -0.7 con un $\mathbb{R}^{2}=94 \%, t=7.3 .0$ sea, los resultados strn virtualmente idénticos estadísticamente. Cosa similar ocurte al repetir las otras dos regresiones, reemplazando el ritmo de crecimiento del empleo urbano por el ritmo de crecimiento del empleo format.
}

al detalle; profesores y médicos; personal de servicio doméstico; funcionarios públicos; mozos y camareros- su expansión puede ser sintomática tanto de progreso como de estancamiento, según el tipo de actividad $y$ oficio que se expande.

El cuadro 5 muestra el crecimiento relativo del empleo terciario, tanto en relación con la pr.s total como en relación con la PEA urbana y secundaria. El peso del sector terciario en la fuerza de trabajo total se eleva fuertemente, al decaer el de las actividades primarias, continuando la tendencia registrada desde 1925. En la fuerza de trabajo urbana la participación terciaria es mucho más estable, manteniéndose en los últimos treinta años en torno a 1.5 veces la del sector secundario ${ }^{12}$. La misma relación se da tanto en países de atto desarrollo, como la Argentina, cuanto de menor desarrollo, como Colombia y Perú, lo que sugiere que quizá haya una relación causal entre ambas, como cree Galenson.

Hay escasa información sobre el tipo de actividad terciaria que se ha ampliado. Los datos de Kaztman (1984) para cinco países muestran que los servicios de más alta productividad y más ligados con la demanda, como los servicios sociales (educación, salubridad y gobierno) y de producción (finanzas, servicios a empresas, almacenamiento), son los que han crecido más rápidamente; en cambio los servicios personales y de distribución, en general de menor productividad, fácil acceso y flexibilidad de ajuste a oferta, son los que han perdido posiciones. No obstante, las conclusiones a base de estos datos no pueden sino ser muy preliminares por ser las observaciones de sólo cinco países, siendo que en cuatro de ellos los datos sólo se refieren al período 1950 1970.

A falta de información sobre la evolución del empleo por subsector del sector terciario, se intentó comprobar la hipótesis de Galenson a base de datos totales para el sector terciario; o sea, que el grueso del empleo terciario se generaba por una demanda derivada del producto secundario. La tecnología industrial moderna absorbería menos empleo por unidad de trabajo que en el pasado -por lo cual el empleo secundario represen-

\footnotetext{
${ }^{12}$ Antes que se considere esta relación excesivamente ajı, cabe señalar que es hoy del orden de 2 a 1 en los países de la oCDE y era ya 1.5 en 1930 en los Estados Unidos.
} 
Cuadro 5

EVOLUCION DE LA COMPOSICION DE LA FUERZA DE TRABAJO EN EL SECTOR SECUNDARIO Y TERCIARIO, 1950-1980

\begin{tabular}{|c|c|c|c|c|c|c|c|c|}
\hline & \multirow{2}{*}{\multicolumn{3}{|c|}{$\frac{\text { PEA secundaria }}{\text { PEA total }}$}} & \multirow[b]{3}{*}{1980} & \multirow[b]{3}{*}{1950} & \multirow{2}{*}{\multicolumn{2}{|c|}{$\frac{\text { PEA terciaria }}{\text { PEA tolal }}$}} & \multirow[b]{3}{*}{1980} \\
\hline & & & & & & & & \\
\hline & 1950 & 1960 & 1970 & & & 1960 & 1970 & \\
\hline América Latina & 18.1 & 20.2 & 22.6 & 25.9 & 25.7 & 30.5 & 34.2 & 38.2 \\
\hline Argentina & 29.9 & 34.5 & 33.2 & 30.4 & 42.1 & 43.1 & 48.4 & 54.1 \\
\hline Brasil & 16.9 & 18.4 & 21.5 & 28.0 & 22.3 & 28.8 & 32.0 & 94.1 \\
\hline Colombia & 15.6 & 16.9 & 20.2 & 22.8 & 23.7 & 28.2 & 36.2 & 42.1 \\
\hline Costa Rica & 15.9 & 17.9 & 21.3 & 23.9 & 26.1 & 30.1 & 35.7 & 41.4 \\
\hline Chile & 25.3 & 25.5 & 27.5 & 25.6 & 87.6 & 39.5 & 42.3 & 48.6 \\
\hline México & 14.1 & 18.5 & 23.0 & 25.4 & 20.4 & 27.2 & 29.1 & 36.1 \\
\hline Perú & 16.1 & 15.9 & 18.9 & 19.2 & 19.9 & 25.7 & 31.8 & 39.6 \\
\hline Uruguay & $\cdots$ & 31.1 & 30.7 & 31.2 & $\therefore$ & 48.1 & 50.3 & 51.1 \\
\hline \multirow[t]{4}{*}{ Venezuela } & 17.6 & 20.1 & 22.9 & 30.0 & 33.5 & 43.0 & 48.4 & 49.0 \\
\hline & \multirow{2}{*}{\multicolumn{4}{|c|}{ PEA secundaria }} & \multirow{2}{*}{\multicolumn{4}{|c|}{$\frac{\text { PEA terciaria }}{\text { PEA urbana }}$}} \\
\hline & & & & & & & & \\
\hline & 1950 & 1960 & 1970 & 1980 & 1950 & 1960 & 1970 & 1980 \\
\hline América Latina & 41.3 & 39.9 & 39.8 & 40.4 & 58.7 & 60.2 & 60.2 & 59.6 \\
\hline Argentina & 41.5 & 44.5 & 40.7 & 36.0 & 58.5 & 55.5 & 59.3 & 64.0 \\
\hline Brasil & 43.1 & 39.0 & 40.2 & 45.1 & 56.9 & 61.0 & 59.8 & 54.9 \\
\hline Colombia & 39.7 & 37.5 & 35.8 & 35.1 & 60.3 & 62.5 & 64.2 & 64.9 \\
\hline Costa Rica & 37.9 & 97.3 & 37.4 & 96.6 & 62.1 & 62.7 & 62.6 & 63.4 \\
\hline Chile & 40.2 & 39.2 & 39.4 & 34.5 & 59.8 & 60.8 & 60.6 & 65.5 \\
\hline México & 40.9 & 40.5 & 44.1 & 41.3 & 59.1 & 59.5 & 55.9 & 58.7 \\
\hline Perú & 44.7 & 38.2 & 36.6 & 32,6 & 5.3 & 61.8 & 63.0 & 67.3 \\
\hline Uruguay & $\cdots$ & 39.3 & 37.9 & 37.9 & $\cdots$ & 60.7 & 62.1 . & 62.1 \\
\hline Venezuela & 34.5 & 31.9 & 32.1 & 38.0 & 65.5 & 68.1 & 67.9 & 62.0 \\
\hline
\end{tabular}

Fuente: PREALC, 1982.

${ }^{2} L a$ PEA urbana equivale a la PEA no agrícola y no minera.

taba menor proporción del empleo urbano que en el pasado europeo y norteamericano-, pero generaria mucho empleo en actividades terciarias, ya que buena parte del comercio y del transporte, los servicios financieros y a las empresas, así como los servicios de educación y salud eran o una demanda derivada del producto secundario o dependían de éste para su financiamiento (el caso de muchos servicios sociales del gobierno). La hipótesis postula que el empleo terciario crecerá con el nivel de industrialización (producto secundario), aunque el empleo secundario no aumente en gran proporción. Por el contrario, si la expansión del empleo terciario respondiera fundamentalmente a una función de absorción de una oferta de trabajo excesiva, y no a una demanda real, se prevería una relación muy floja entre el ritmo de crecimiento del empleo terciario y el del producto secundario (gráfico n). Se ve que hubo una relación positiva, fuerte y significativa entre estas dos variables en 1950-1980. ${ }^{13}$. Puede así rechazarse la hipótesis de sobreterciarización. Más bien se avala la tesis de que el grueso del crecimiento del empleo terciario obedeció a una creciente demanda de empleo productivo, y no fue excesivo, lo que habría sido sintomático de un subempleo creciente.

\footnotetext{
${ }^{13} \mathrm{La}$ regresión simple es: el ritmo de crecimiento del empleo terciario $=-0.4+(0.68)$ (el ritmo de crecimiento del producto secundario). $R^{2}=93 \%, t=6$.
} 
Gráfico $1 \mathrm{I}$

CRECIMIENTO DEL EMPLEO TERCIARIO EN COMPARACION CON EL. CRECIMIENTO DEL PRODUCTO SECUNDARIO 1950.1980

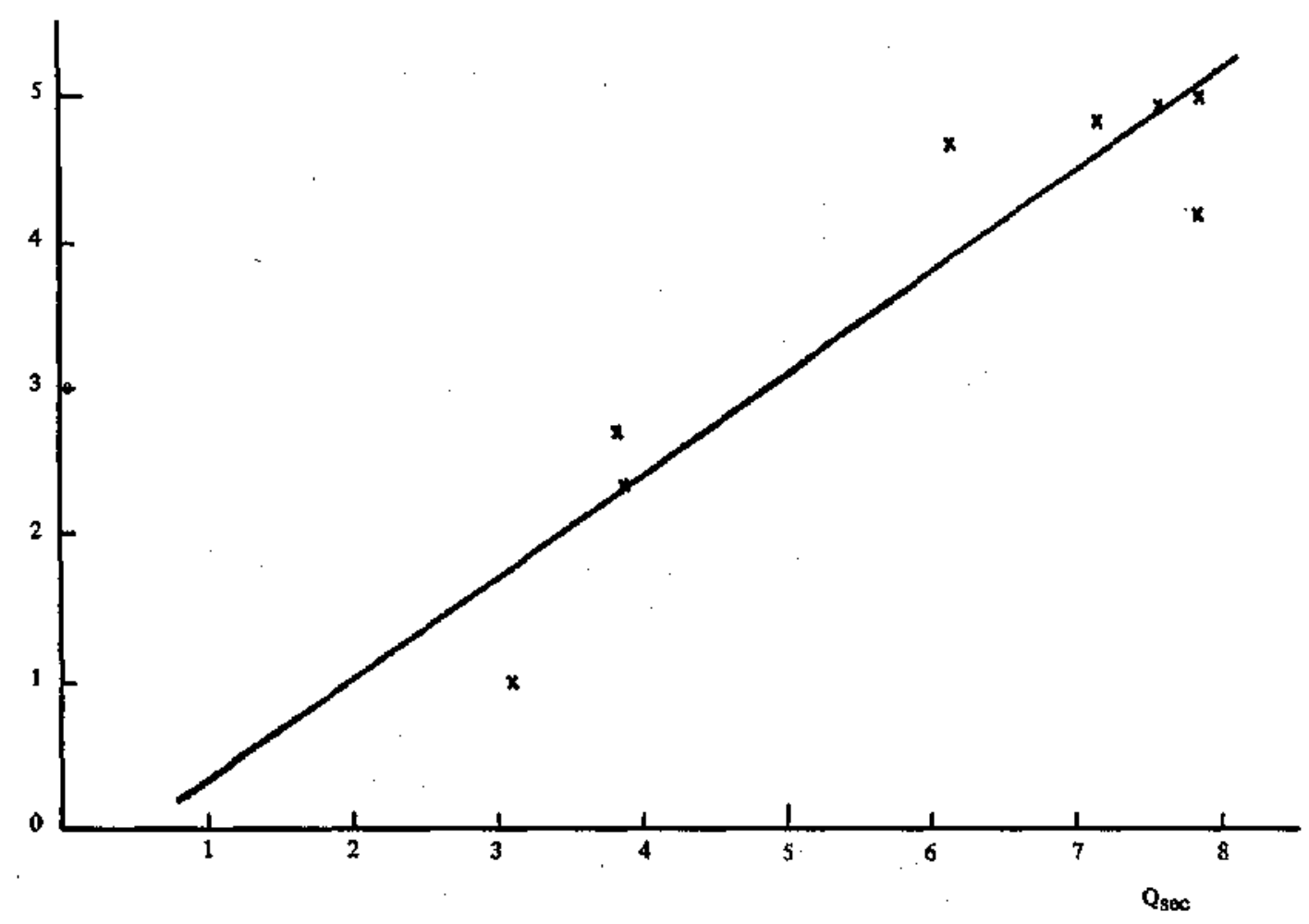

III

\section{Evolución de la productividad}

Por importantes que fueran los cambios en la composición sectorial de la fuerza de trabajo en América Latina, más relevantes fueron los habidos dentro de cada sector, reflejados en pronunciadas mejoras en la productividad sectorial (producto por hombre). Entre 1950 y 1980 el producto por trabajador en América Latina aumentó 2.4 veces; de 1150 a 2750 dólares (cuadro 6). De este aumento, $25 \%$ se debió a una mayor productividad proveniente de la reducción de 20 puntos porcentuales en la fuerza de trabajo en actividades primarias de baja productividad y su traslado a empleos en los sectores secundarios y terciarios con niveles de productividad de 3 a 5 veces superiores. $O$ sea, de haberse mantenido los niveles de productividad sectorial de 1950 , la producti- vidad de la economía latinoamericana en 1980 habría subido sólo $25 \%$. El $90 \%$ restante (que entra en forma multiplicativa, $1.9 \times 1.25=2.4$ ), se debio a alzas de la productividad dentro de cada sector.

Aunque eran grandes las diferencias de productividad entre sectores - de un máximo de 8 y 9 a 1 en Brasil y México a un mínimo de 2 a 1 en Argentina en 1950- se redujeron en los treinta años (cuadro 6), llegando en 1980 a un máximo de 6 y 7 a l en Brasil y México y a un mínimo de 1.4 a 1 en Argentina. Por lo demás, con raras excepciones y como era de esperar, fue la productividad sectorial inicialmente más baja, es decir, la del sector primario, la que se elevó más rápidamente; y las más alta en un comienzo - la 
de la actividad terciaria - la que subió con mayor lentitud (cuadro 7), aunque de todas maneras creció en esos treinta años a un promedio no despreciable de $1.8 \%$ con bastante variación entre países y períodos. Es difícil conciliar este cre- cimiento de la productividad media del sector terciario con un aumento importante en la proporción del sector ocupado en actividades absorbentes.

Los grupos ocupacionales de más rápịdo cre-

Cuadro 6

NIVELES Y CRECIMIENTO DE PRODUCTIVIDAD Y PRODUCTIVIDAD RELATIVA SECTORIAL, 1950-I980)

\begin{tabular}{|c|c|c|c|c|c|c|c|c|}
\hline & \multicolumn{4}{|c|}{$\begin{array}{l}\text { Niveles de productividad } \\
\text { (Dólares de 1970) }\end{array}$} & \multicolumn{4}{|c|}{$\begin{array}{l}\text { Tasas de crecimiento de la } \\
\text { productividad (anual) }\end{array}$} \\
\hline & 1950 & 1960 & 1970 & 1980 & $1950-60$ & $1960-70$ & $1970-80$ & $1950-80$ \\
\hline Primario & 480 & 670 & 840 & 1060 & 3.3 & 2.3 & 2.4 & 2.6 \\
\hline Secundario & 1600 & 2100 & 2780 & 3500 & 2.8 & 2.8 & 2.3 & 2.7 \\
\hline Terciario & 2280 & 2500 & 3130 & 3840 & 1.0 & 2.2 & 2.1 & 1.8 \\
\hline \multirow[t]{4}{*}{ Total } & 1150 & 1520 & 2060 & 2750 & 2.9 & 3.1 & 2.9 & 3.0 \\
\hline & \multicolumn{4}{|c|}{ Productividad secundaria } & \multicolumn{4}{|c|}{ Productividad terciaria } \\
\hline & \multicolumn{4}{|c|}{ Productividad agropecuaria } & \multicolumn{4}{|c|}{ Productividad agropecuaria } \\
\hline & 1950 & 1960 & 1970 & 1980 & 1950 & 1960) & 1970 & 1980 \\
\hline América Latina & 3.9 & 3.9 & 4.1 & 4.1 & 5.5 & 4.7 & 4.6 & 4.5 \\
\hline Argentina & 1.6 & 1.3 & 1.5 & 1.4 & 2.1 & 1.7 & 1.4 & 1.1 \\
\hline Brasi] & 6.9 & 7.8 & 7.8 & 7.3 & 8.2 & 7.0 & 7.6 & 7.6 \\
\hline Colombia & 1.8 & 2.1 & 1.8 & 1.4 & 2.7 & 2.4 & 1.9 & 1.6 \\
\hline Costa Rica & 1.8 & 1.9 & 1.8 & 2.1 & 3.6 & 3.7 & 2.5 & 2.4 \\
\hline Chile & 3.2 & 3.8 & 4.5 & 3.7 & 3.6 & 3.9 & 4.2 & 3.5 \\
\hline México & 5.3 & 4.0 & 4.7 & 5.0 & 9.4 & 6.7 & 7.1 & 6.3 \\
\hline Uruguay & $\ldots$ & 1.7 & 1.3 & 1.7 & $\ldots$ & 2.2 & 1.7 & 1.9 \\
\hline Venezuela & 5.0 & 4.3 & 3.3 & 2.4 & 9.6 & 5.2 & 3.9 & 3.4 \\
\hline
\end{tabular}

Fuente: PRFAl.c, 1982; para el producto sectorial, datos de la División de Estadistica cle la c:E.PAl, basados en cifras oficiales.

Cuadro 7

EVOLUCION DE LA PRODUCTIVIDAD SECTORIAL POR PAIS, 1950-1980

(Tasas de crecimiento antual)

\begin{tabular}{|c|c|c|c|c|c|c|c|c|c|c|c|c|c|}
\hline \multirow[b]{2}{*}{ Sectores $^{4}$} & \multicolumn{3}{|c|}{$1950-1960$} & \multicolumn{3}{|c|}{$1960-1970$} & \multicolumn{3}{|c|}{$1970-1980$} & \multicolumn{4}{|c|}{$1950 \cdot 1980$} \\
\hline & $\mathbf{P} \quad$ & $\mathbf{S}$ & - $\mathrm{T}$ & $P$ & . $\mathbf{s}$ & $\mathbf{T}$ & $\mathbf{P}$ & - $\mathbf{S}$ & $\mathbf{T}$ & $\mathbf{P}$ & $\mathbf{S}$ & - & $\mathbf{T}$ \\
\hline Argentina & 3.3 & 0.5 & 0.6 & 3.9 & 4.6 & 0.8 & 2.3 & 1.9 & -0.1 & 3.1 & 2.3 & & .4 \\
\hline Brasil & 3.4 & 4.6 & 1.6 & 2.0 & 1.6 & 2.3 & 4.9 & 3.8 & 4.6 & 3.4 & 3.3 & & .8 \\
\hline Colombia & 2.3 & 3.6 & 1.1 & 3.0 & 1.5 & 0.3 & 3.3 & 1.0 & 2.1 & 2.9 & 2.0 & & .2 \\
\hline Costa Rica & 2.6 & 3.5 & 2.9 & 4.0 & 3.0 & - & 0.7 & 2.4 & 0.2 & 2.4 & 3.0 & & 1 \\
\hline Chile & 1.7 & 3.1 & 2.0 & 2.7 & 3.3 & 2.4 & 1.9 & -0.7 & -0.4 & 2.1 & 1.9 & & .4 \\
\hline México & 4.2 & 1.3 & 0.5 & 2.6 & 3.9 & 2.9 & 3.1 & 2.4 & 0.8 & 3.3 & 2.5 & & .4 \\
\hline Perú & 3.9 & 6.4 & 1.3 & 4,0 & 2.0 & 0.7 & 0.2 & 0.6 & -0.9 & 2.7 & 3.0 & & 0.4 \\
\hline Uruguay & - & 0.2 & - & 2.3 & 0.2 & - & 1.7 & 4.0 & 2.5 & $2.0^{\mathrm{b}}$ & $2.1^{b}$ & & $1.2^{\mathrm{b}}$ \\
\hline Venezuela & 7.1 & 4.3 & -0.4 & 2.5 & 1.7 & 1.6 & -2.8 & -0.7 & 1.2 & 2.2 & 1.8 & & .8 \\
\hline
\end{tabular}

Fuente: PREALc, 1982; para el producto sectorial, datos de la División de Estadística de la cirpal, basados en cifras oficiales.

$$
\begin{array}{ll}
* \mathbf{P}=\text { sector primario } & T=\text { sector terciario } \\
\mathbf{S}=\text { sector secundario } & \text { '1960-1980 }
\end{array}
$$


cimiento en este periodo fueron los empleados calificados (profesionales, técnicos y oficinistas), que crecieron a un ritmo del orden del $6 \%$ anual entre 1950 y 1970 (único periodo con información), tasa muy superior a la de la pes (2.3\% anual) o de la población en edad de trabajar (2.7\% anual) o la de la PEA urbana (3.6\% anual) para el mismo período (cuadro 8). Como estos empleados representan la mano de obra más calificada y como el grueso de ellos se encuentran en las actividades terciarias, tiene que haber habido un fuerte mejoramiento en el nivel de calificación de la mano de obra terciaria. Es más, como el ritmo de crecimiento anual de la PEA correspondiente a empleados de este tipo (6\%) fue inferior al crecimiento estimado en la fuerza trabajadora con una escolaridad superior a la primaria $(8 \%)$ en ese mismo perfodo 1950-1970 (cuadro 8), ello implica que: i) el crecimiento inferior pero rápido de los empleados de alta calificación centrados en el sector terciario respondió a aumentos en la demanda de sus servicios más que a su mayor oferta $y$, ii) que otros trabajadores, y no sólo los empleados, sino, sobre todo, los obreros urbanos $^{14}$ también deben haber elevado su nivel

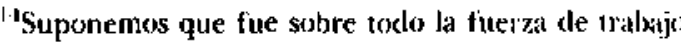
urbana la que mejoró su escolaridad por efecto de la ampliación y mejor calidad del sistema de ensenanza en las ciudarles y la mayor selectividad de la nigración rural-urbana. según su grado de escolaridad
}

medio de calificación (al menos de escolaridad). O sea, hubo una fuerte profesionalización de la fuerza de trabajo urbana en el período que, de por sí, debe haber tendido a elevar la productividad sectorial.

Incluso mejor que los datos sobre productividad $\rightarrow$ si no fuera que la información disponible es tan esporádica y fragmentaria- son los que se refieren a salarios. Estos muestran que los correspondientes a mano de obra urbana poco calificada son muy superiores a los rurales; incluso los salarios del sector urbano informal son superiores a los rurales. ${ }^{15}$ Así, pues, deben descartarse - por lo menos para América Latina- hipótesis que atribuyen la migración a la atracción que ejercen los salarios artificialmente altos del sector formal urbano, pues hasta los salarios no abultados del sector informal son superiores a los rurales, y no inferiores como implican los modelos de Harris, Todaro y Fields.

Por otro lado, aunque la evolución de los salarios reales urbanos muestra un comportamiento algo irregular - de ciclos coyunturales

\footnotetext{
1.5.1:PAl. (1973) y Erikson (1961) sugieren diferencias a menos del orden de 2 a 1 . Por cierto, pexlria liaber diferencias no monetarias entre ambas zonas. pero no es claro si todas esas diferencias (educación $\psi$ salubriclad, por ejemplos) seat! siempre y sistemáticamente inferiores en la citdad. Por $k$ demás, es altamente improbable que alcanzarat a compensar diferencias de $100 \%$ en el ingreso monetario.
}

Cuadro 8

CRECIMIENTO DE LA PEA CALIFICADA, 1950-1970

(Tasas de crecimiento antal)

\begin{tabular}{|c|c|c|c|c|c|c|}
\hline & PEA & $\begin{array}{l}\text { Población } \\
\text { en edad de } \\
\text { trabajar }\end{array}$ & $\begin{array}{c}\text { PEA } \\
\text { urbana" }\end{array}$ & $\begin{array}{c}\text { PEA } \\
\text { formal }\end{array}$ & $\begin{array}{l}\text { PEA personal } \\
\text { calificado }^{\mathbf{b}}\end{array}$ & $\begin{array}{l}\text { PEA con estudios } \\
\text { superiores a } \\
\text { educación primaria }\end{array}$ \\
\hline América Latina & 2.3 & 2.7 & 3.6 & 3.7 & 6.1 & 8.4 \\
\hline Argentina & 1.5 & 1.8 & 2.1 & 2.2 & $2.3^{5}$ & 10.8 \\
\hline Brasil & 2.7 & 3.0 & 4.3 & 4.3 & 6.5 & 8.5 \\
\hline Colombia & 2.5 & 2.9 & 4.4 & 5.0 & 8.1 & $\ldots$ \\
\hline Costa Rica & 3.1 & 3.5 & 4.7 & 5.1 & 6.0 & 7.9 \\
\hline Chile & 1.4 & 2.3 & 2.0 & 2.8 & 2.3 & 2.8 \\
\hline México & 2.5 & 3.0 & 4.7 & 4.9 & 5.9 & 5.9 \\
\hline Uruguay & 1.2 & $1.1^{\mathrm{c}}$ & $1.3^{\mathrm{r}}$ & $1.3^{x}$ & $2.7^{r}$ & 4.4 \\
\hline Venczuela & 3.1 & 3.7 & 4.8 & 4.8 & 6.6 & 9.6 \\
\hline
\end{tabular}

Fuente: CEPAL, I981: Ramos, 1970 y PREALC, 1982.

"La PEA urbana equivale a la PEA no agrícola y no minera.

bProfesionales, técnicos y oficinistas.

1960-1970. 
(relacionados con las políticas de estabilización que siguieron a las dos alzas de tos precios de los productos energéticos) superpuestos a una tendencia alcista secular (PREAl.c, 1982, cuadro III3)-, los datos disponibles no muestran ninguna tendencia sistemática a que los salarios informales (o su indicador indirecto, los salarios de la construcción) caigan, o crezcan menos que los del sector formal (los sectores industriales cubiertos por encuestas salariales). ${ }^{16}$ De haber subido sistemáticamente, la presión de una mayor oferta de trabajo urbana se habría manifestado en caidas en los salarios informales y de la construcción. Que éstos hayan mantenido su relación con los salarios del sector industrial formal sugiere que no existió esa mayor presión de la oferta de trabajo urbana o (lo que sostengo) que fue (afortunadamente) compensada por una demanda aún mayor de trabajo productivo, demanda genuina derivada del mayor crecimiento del producto urbano (secundario y terciario). O sea, primó el peso de una mayor demanda de trabajo.

\section{IV}

\section{Problemas y formas de ajuste}

El hecho de que en el período 1950-1980 la demanda de trabajo se haya elevado en general más que la oferta, no significa que no ocurrieran problemas ocupacionales. Dentro de esta tendencia general, fuerte y positiva, hubo periodos y países que experimentaron problemas; en igual forma, hubo grupos de trabajadores cuya situación se deterioró en términos absolutos, como sucedió con la caída absoluta de la productividad terciaria en el decenio de 1970-1980 en Argentina, Chile y Perú (cuadro 7). Además, el empleo terciario creció más rápidamente que el producto secundario en los años setenta: $2.7 \%$ frente a 2.6\% anual (Argentina), 4.0\% frente a $1.1 . \%$ anual (Chile) y $4.9 \%$ frente a $3.4 \%$ anual (Perú). De ahí que la relación entre crecimiento del empleo terciario y el producto secundario fuese tan débil en 1970-1980, ${ }^{17}$ y se apartase tan marcada-

\footnotetext{
${ }^{16} \mathrm{El}$ informe citado distingtze según sector de la construccion (indicador indirecto del sector informal) o sector industrial (indicador indirecto del sector formal). Los peros trabajos que comparan directamente la evolución salarial en los sectores formal e informal dan resultados similares (Gre. gory, 1980; Pfeffermann y Webb, 1979; PRE.Al.c, 1980).

${ }^{17}$ Por lo menos en Argentina y Chile es posible que parte de ese crecimiento del empleo terciario no haya sido espurio sino real, por obedecer a una temandd'de trabajos proveniente de una mayor importación de bienes e ingreses de capital como la que caracterizó al período de apertura finamciera comercial. También es posible que este factor haya obrado, aunque en menor grado, en los demás países de la reygión en
}

mente de los buenos resultados obtenidos en 1950-1980, y los decenios de 1950 y 1960 por separado. ${ }^{18}$

Cuando el crecimiento del empleo terciario va acompañado por aumentos en el desempleo urbano, es bastante probable que obedezca más bien a presiones de la oferta que de la demanda. Este fue el caso de Chile, cuya tasa de desempleo media entre 1975 y 1980 fue del orden de dos y très veces la histórica. Sin embargo, a menudo el ajuste a una demanda insuficiente de trabajo se manifiesta no en aumentos de la cesantía sino en incrementos del subempleo. Por ejemplo, a raíz de la política de estabilización y liberalización seguida en Argentina de 1975 en adelante, el empleo asalariado industrial descendió en un tercio. Pese a ello, la tasa de desempleo se mantuvo por debajo del $5 \%$. Se incremento el empleo por cuenta propia lo suficiente para compensar la caida en el empleo asalariado. (Proyecto Gobier.

ese período por la mayor afluencia de capitales externos que tuvieron todos, con el nuayor volumen de bienes importados para comercializar y la mayor actividad tinanciera que ello implicaba. De ser asi, este fenomeno no ha de continuar en el decenio de 1980, para el cual se prevé una desaceleración en la entrada de capital.

${ }^{1 *}$ La relación siguió siendo positiva, pero no estadísticamente significativa en 1970-1980; en canbio, fue positiva, fuerte y significativa en 1950-1960, 1960-1970 y en todo el periodo $1950-1980$. 
no Argentino - PNUD-OIT, 1980 a) y b) y Lagos y Tokman, 1983.) Y como los despedidos recibían importantes indemnizaciones -pues en Argentina buena parte de la fuerza de trabajo se ocupa en grandes empresas- el empleo por cuenta propia proporcionó un ingreso decente (aunque el grueso fuera retribución al capital más que a la mano de obra). Además, como tener dos empleos era bastante frecuente, gran parte de la reducción de la demanda se manifestó no tanto en desempleo, como en pasar a tener un solo trabajo. Por último, una elevada proporción de la reducción de la demanda recayó sobre los trabajadores migrantes, así que no afectó mayormente la tasa de desempleo, sino la de migración.

Otra variante de ajuste se dio en el Perú, entre 1975 y 1978. Más que elevar la tasa de desempleo - la cual efectivamente no subió en gran proporción- el retroceso económico de esos tres anos frente a una continua y fuerte oferta de trabajo resultó en mayor subempleo por concepto de bajos ingresos; es decir, se elevó la proporción de personas en la fuerza de trabajo que, con trabajar 35 horas o más a la semana, ganaban menos que el salario mínimo. Esto afectó, en particular, a la fuerza de trabajo secundaria-jóvenes, mujeres y viejos-, que se empleaban en actividades de bajos ingresos y escasa productividad, que normalmente no habrian aceptado, pero que en estas circunstancias de crisis eran aceptables, al menos transitoriamente, para complementar el reducido ingreso familiar. De ahi que se hayan observado en estos tres años importantes aumentos en las tasas de participación, en especial las femeninas, y una expansión significativa de los familiares no remunerados. Por último, parece haber habido una mayor incorporación de jóvenes a la fuerza de trabajo en la forma de aprendices - ya que no era posible encontrar otro trabajo adecuadamente remuneradopues esto era un resquicio legal para evadir el pago del salario mínimo (Henríquez e lguiñiz (comp.), 1983; R. Grampone, 1983; Verdera, 1983; y Wicht, 1983).

Estos tres países, sugieren claramente que el empleo generado no fue respuesta a una mayor demanda de trabajo productivo sino a una mayor oferta, es decir, la mayor oferta creó su propia demanda, inflando las actividades urbanas de más fácil acceso donde el subempleo siempre puede 'generarse', simplemente repartiendo los años-hombre de trabajo disponibles entre mayor número de personas.

Con todo, es de señalar que, con una sola excepción, ${ }^{19}$ estos tres casos fueron los únicos en treinta años (y en el decenio de 1970) en que el crecimiento del empleo terciario superó al del producto secundario. No deja de ser sugestivo que sean los tres casos de más lento crecimiento del producto secundario en los treinta años. $O$ sea, de ascender con vigor el producto secundario, no se darían caidas en la productividad terciaria ni probablemente los aumentos consiguientes del subempleo.

Aunque la situación ocupacional general tendió a mejorar o no empeorar en esos patses que acusaron un crecimiento económico fuerte y estable, tampoco estuvieron exentos de problemas de empleo. Por ejemplo, el Brasil vivió un proceso de marcado desarrollo entre 1965 y 1980 , pero sus beneficios se repartieron en forma muy desigual, entre regiones, sectores rurales y urbanos, y al interior del sector urbano y el propio sector moderno. En particular, y en lo que concierne al empleo, aunque en el decenio de 1960 el empleo moderno creció intensamente, dentro del sector moderno se elevó la demanda de trabajo calificado (técnicos y empleados mucho más que de fuerza trabajadora no calificada). De ahi que los salarios de los menos calificados en este período hayan caído con relación a los calificados y que el ritmo de crecimiento de los puestos de trabajo para mano de obra calificada en el sector moderno haya sido cuatro veces mayor que para la de trabajo no calificado (Pfeffermann y Webb, 1979; Bacha, 1977; Wells, 1974, y Pastore y Cabral de Castro, 1983).

Además, como ha seguido siendo importante la oferta de mano de obra poco calificada, ha habido que crear otras fuentes de empleo para absorberla. Por ello, en este período se da cierta 'urbanización' de la fuerza de trabajo agricola, en especial en el estado de São Paulo; es decir, los trabajadores agrícolas emigran a la ciudad, por falta de tierra o trabajo regular en el campo, pero se ocupan en labores agrícolas como trabajadores

'"El Uruguay en el decenio de 1960, cuando el empleo terciario crecio a un ritmo de $\mathrm{J} .6 \%$ anual mientras el produc. to secundario se elevaba en I\% anual. 
temporales (boias frias o volantes) en las épocas de mayor demanda.

Todo lo anterior no obsta a que, en general, haya mejorado la situación del empleo en Brasil en ese período; sólo implica que empeoró la situación relativa de los pobres urbanos. Sin embargo, se elevó su nivel absoluto de ingresos gracias al pujante crecimiento económico del período, y mejoró mucho más en todo sentido en comparación con la crisis de 1981-1983, cuando se desplomó el producto brasileño.

El proceso de crecimiento de muchos países fue acompañado por importantes desequilibrios regionales y, en particular, por una suerte de metropolización de la fuerza de trabajo. El crecimiento de ciudad de México sea tal vez el ejemplo más elocuente de este fenómeno, pues su población casi se triplicó en 1960-1980. Gracias al sólido crecimiento económico de postguerra, fue dinámica la evolución general del empleo del país. Esta tendencia general, sin embargo, ocultaba un fenómeno peligroso; hasta el auge petrolero, las calificaciones exigidas eran cada vez más rigurosas, pues la expansión económica se basa- ba en procesos de uso cada vez más intensivo de capital. La bonanza petrolera y, en particular, el alza de sus precios produjeron un vuelco total en esa situación. Fue tan grande el aumento de los ingresos del país - por el alza en los precios de los energéticos- que se generó una demanda de trabajo de todo tipo, calificado o no, en especial en el sector terciario. Sin embargo, este empleo era muy dependiente de la liquidez que producía el auge petrolero. Cuando resultó ser transitorio (1982), esa mano de obra urbana, recién inmigrada, quedó en situación muy precaria. Por su escasa preparación, no pudo integrarse a los empleos más calificados del sector secundario urbano. Incapaz de desenvolverse en trabajos del sector urbano formal y ya arrancado de su medio habitual de sostén económico en las zonas rurales, este grupo de trabajadores engrosó las filas del subempleo y el desempleo urbanos. Este último, la manifestación más aguda del problema ocupacional, se elevó súbitamente de poco más de $4 \%$ en 1981 a casi $13 \%$ en 1983 (Muñoz, Oliveira y Stern, 1977; Garcia, Oliveira y Muñoz, 1980; Trejo, 1973; y Gregory, 1981).

\section{Conclusiones}

Las transformaciones en la composición sectorial de la fuerza de trabajo, el sostenido crecimiento del empleo secundario y formal, y sobre todo la fuerte elevación de la productividad ( $y$ los salarios) dentro de cada sector, avalan la conclusión de que el gran aumento de la fuerza trabajadora urbana en América Latina durante la postguerra fue reflejo de una vigorosa demanda de trabajo productivo (signo positivo) más que de la aceleración en la oferta (signo de debilidad). De ahí que en general se produjera una dinámica industrialización, sin excesos mayores de urbanización, informalización o terciarización.

Que asi ocurriera fue fortuito pues, ceteris paribus, era de temer que la explosión demográfica del decenio de 1950 exacerbara los problemas del empleo en los decenios siguientes. No obstante, en vista del crecimiento sin precedente del producto de la región, pudo absorberse esta mayor oferta de trabajo, no sólo sin que decayera la productividad, sino, como se ha visto, elevándola considerablemente en todos los sectores.

Desde luego que de no haberse acelerado el ritmo de crecimiento del producto, otro habria sido el desenlace. En efecto, la crisis postpetrolera de 1979 se tradujo en 1980-1983 en un descenso del producto per cápita de la región, con la caída consiguiente en la demanda de trabajo y una súbita elevación en el desempleo en la mayoría de los paises de la región.

El hecho de que en 1950-1980 el crecimiento económico fuera suficiente como para absorber productivamente el grueso de una fuerza de trabajo urbana no implica que no se hayan planteado problemas. A menudo afloraron el desempleo y el subempleo urbano o hubo sobreterciari- 
zación en períodos de lento crecimiento económico (por ejemplo en Argentina, Chile y Peró); incluso se dieron problemas particulares en países con un fuerte crecimiento económico y sin problemas ocupacionales generales como, por ejemplo, con respecto a la fuerza de trabajo no calificada (Brasil) o la metropolitana (México). No obstante, se tendió a confirmar el sentido común. Sin crecimiento económico se agudizan los problemas de empleo; con crecimiento, tienden a resolverse. Tal vez la relación no sea estrictamente lineal, pero la experiencia de postguerra en la región muestra que el crecimiento económico fue decisivo para aminorar los problemas del empleo. Además el ejemplo inverso confirma este resultado: en la crisis económica que sufrió la región en 1981-1983, en que el producto per cápita declinó por primera vez desde el decenio de 1930 durante tres años consecutivos, el desempleo se elevó marcadamente.

Que no se haya notado esta creciente demanda de trabajo en 1950-1980, sino, por el contrario, que se haya temido que el problema del empleo hubiera empeorado en el periodo, se debió en parte a lo muy presente que tenían los observadores el acelerado crecimiento de la población en edad de trabajar, $y$ por consiguiente, la necesidad de generar empleo. También se debió a que entre 1925 y 1955 el empleo manufacturero habia aumentado lentamente (2.2\%) pese a un sostenido incremento del producto sectorial (4.9\%); o sea, el sector secundario absorbio empleo a un ritmo equivalente sólo al $45 \%$ del crecimiento de su producto. Felizmente, esta capacidad de absorción creció en los treinta años siguientes, de tal modo que en el decenio de 1970 el empleo secundario se amplió a un ritmo igual al $65 \%$ del incremento del producto sectorial. Es probable que esta creciente generación de empleo del sector secundario se debiera a que en los albores de la industrialización en América Latina fueron enormes los aumentos de productividad que acompañaron a la introducción de la industria moderna, pues la industrialización era tardía. ${ }^{20}$ Al continuar el proceso, sin embargo, las diferen-

\footnotetext{
${ }^{201}$ Esta fue una hipótesis que formule por primera vez sobre la base de datos para 1950-1960 (Ramos. 1970). La aceleración posterior del empleo secundario parecería conEirmarla para el período 1960-1980.
}

cias de productividad se irían acortando, ya que el común de la industria existente sería cada vez menos tradicional. Dicho de otra manera, por muy rápidamente que se ampliara el empleo secundario moderno (y calificado) no se elevaría marcadamente el empleo secundario total hasta que no fuese relativamente bajo el componente de empleo secundario tradicional (o subempleo secundario) por absorber. De ahi que no seria hasta los decenios de 1960 y 1970 que se acelerase y notase el crecimiento del empleo secundario.

Como sostenía Galenson, el fuerte crecimiento del empleo terciario en el período parece haber estado ligado al crecimiento del producto secundario, lo que muestra la estrecha relación recíproca que existe entre los sectores. Sin embargo, como muchas actividades del sector terciario son de fácil acceso, esta ligazón admite excepciones en que predomina la presion de oferta, cuando el sector terciario cumple la función de absorber excedentes de mano de obra.

Pese a que en este período la demanda de trabajo urbano aumentó con celeridad mayor que la oferta, se habria registrado una corriente migratoria aún con un crecimiento lento de esa demanda, pues los salarios en la ciudad, tanto en el sector formal como el informal, eran muy superiores a los rurales. Sostengo que se ha mantenido ese desequilibrio, o sólo se ha corregido en parte, pese a la migración, porque, por efecto de una variedad de causas, el progreso tecnologico ha tendido a difundirse más rápidamente en la industria que en la agricultura, elevándose por consiguiente la productividad del capital y de la mano de obra con velocidad mayor en la ciudad que en el campo.

En el fondo, el mercado de trabajo no ha sido uno, integrado y equilibrado, sino que ha habido dos mercados de trabajo, uno rural y otro urbano, en estado de desequilibrio, como si se tratara de dos países, con una movilidad imperfecta entre ambos. No ha emigrado a la ciudad en busca de mayores salarios toda la mano de obra necesaria para igualarlos, ni han acudido al campo desde la ciudad todo el capital, la tecnología y la capacidad empresarial necesarios en procura de la mayor rentabilidad que podrian obtener por su escasez relativa para igualar la productividad. De ahí que el modelo más útil para comprender la corriente migratoria hacia las ciudades sea el 
de dos paises: uno pobre rural, el otro rico y urbano, con diferentes dotaciones de capital, tecnología y capacidad empresarial por trabajador, mayor en la ciudad que en el campo, con una movilidad lenta de todos los factores, $y$, por consiguiente, con importantes diferencias de productividad y retribución a los factores en el tiempo. Así pues, el nivel salarial en cada zona está en gran parte determinado por la escasez o abundancia relativa de los factores dentro de cada zona como si fueran dos países y no tanto por la dotación de factores en ambos (como si fueran un solo país). Corregir la diferencia de salarios urbano-rural requeriria encauzar más tecnologia, capital y capacidad empresarial de la ciudad al campo y promover activamente una aceleraciớn de la migración hacia la ciudad. Sólo así tenderán a igualarse los niveles de productividad sectorial en la economía.

Debido a estas diferencias de productividad y mientras perduren, persistirá una migración hacia la ciudad aunque no aumente la demanda de trabajo productivo urbano. Por este motivo, es necesario que un sector - como el terciarioabsorba esta mano de obra poto calificada que viene del campo, en actividades de productividad aún baja, pero superior a la rural. El sector terciario se ampliará por razones de demanda (con el producto secundario) en momentos de auge economico -como sostiene Galenson-y se expandirá cediendo a la presión de la oferta, producto de la urbanización, en etapas de estancamiento. Ambos comportamientos son posibles: predominó el primero en el período 1950-1980, cuando se registró un período de marcado crecimiento económico para la mayoría de los pafses de la región. Es de suponer, en cambio, que en la recesion de 1981-1983 han predominado las presiones de la oferta, lo que ha dado lugar a un mayor desempleo y subempleo en las ciudades.

\section{Bibliografia}

Bacha, E. (1977): Issues and evidence on recent Brazilian economic growth. Developnemt. Enero-febrero.

Brasil, Gobietno del (1978): O trabatho volonte na agriculiura pautista. Ministerio de Trabalho, Secretaria de Emprego e Salario.

CELADE (Centro Latinoamericano de Demografía) (1983): Boletn demografico, año $\mathrm{x}, \mathrm{N}^{\prime \prime}$ 32. Santiago de Chile, julio.

CEPAL (Comisión para América Latina) (ISK5): Los cambios estructurales en el empleo en el desarroila económico de América Latina. Boletín peonómico de Américn Latim, vol. $\mathrm{x}, \mathrm{N}^{*} 2$, octubre.

(1973): Distribución comparada del ingreso en algunas grandes ciudades de América Latina y en los países respectivos. Boletín económico de América Latina, vol. X'III, $\mathrm{N}^{\text {(I) }} 1$ y 2. Latina.

(1978): Series históricas del crecimiento de America

(1981): Anuario estadtstico de América Latina, 1980.

Erikson, J.R. (1966): Wage structures in economic develupment in Latin American countries: a comparative andysis (tesis de prueba para optar al doctorado). Berkeley, Estados Unidos: Universidad de California.

Fieids, C. (1975): Rural-urban migration, urban unenuployment and underemployment and job search activity in L.DCs. Journal of denelopment economics. Junio.

Galenson, W. (J963): Economic development and the sectorial expansion of employment. Retnista internacional det mabajo. Junio.
Garcia, N. (1979): México: la pequeña industria en una estrategia de empleo productivo. Investigaciones sobre empleo N"17. Santiago de Chile: PREALC.

García, B., O. de Oliveira y H. Muñoz (1980): Tres ensayos sebre migraciones intemas. México: Universidad Nacional Autónoma de México, Instituto de Investigaciones Sociales.

Gregoty, P. (1981): Ecomomic development and the labour market in Mexico, Research Paper Series $\mathrm{N}^{\circ} 8$. University of New Mexico.

Grompone, R. (1983): Sector informal y algunas políticas promocionales de empleo en Lima Metropolitana. Lima, una metrópuli: 7 debotes. Lima: Centro de Estudios y Promoción del Desarrollo (nEsco).

Harris, J. y M. Todaro (1970): Migration, unemployment and development: a two-sector analysis. American economic review. Marzo.

Henrlquez, N. y J. Iguiñiz (comp.) (I983); El problema del emplev en el Perú. Universidad Católica del Perú, Fondo Editorial.

Kaztman, R. (1984): Notas sobre las transformaciones sectoriales del empleo en America Latina. Revista de la SEPAt, $\mathrm{N}^{2} 24$, diciembre.

Lagos, R. y V. Tokman (1988): Monetarismo global, empleo y estratificación social: los casos de Argentina y Chile. Movilidad acupacional y mercados de trabajo. Santiago de Chile: PRr.al.c., 
Muñoz, H., O. de Oliveira y C. Stetn (1977): Migración y destgualdad social en la Ciudad de Méxica. Universidad Nacional Autónoma de Méxiç y El Colegio de México.

Pastore, J. y M. Cabrai de Castro (1983): Cambios ocupacionales, movilidad y desigualdad social en Brasil. Moviltdad ocupacional y mercados de trabajo. Santiago de Chile: PKEALC:

Pfeffermann G. y R. Webb (1979): The distribution of income in Brazil. World Bank Staff Working Paper N 356 , septiembre

Piñera, S. y M. Selowsky (1976): El precio social del trabajo y el retorno social de inversiones en educación en mercados laborales segmentados. Cuadernos de economía. Santiago de Chile: Unjversidad de Chile, diciembre. (Tambien apareció en Quarterly joumal of econumics, agosto de 1978).

PREALC (Programa Regional de Empleo para América Latina y el Caribe-orr) (1980): Los trabajadores por cuenta propia en Santiago. Documento de trabajo $\mathrm{N}^{\circ} 184$.
(1982): Mercado de trabuigen rifras: 1950-80. Santiago de Chile. Proyecto Gobierno Argentino-pNud-(o)T (1980a): El mercado de trabajo est Argentina: cuvactertsticas y tendencias principales, Buenos Aires: Ministerio del Trabajo.

(1980b): El sector cuenta prupia. Estudio sacioeconómico del trabajo independiente y de la miniempresa en la Capital Federaly en el Gran Buenus Aires. Buenos Aires: Ministerio del Trabajo.

Ramos, Joseph (1970): Labor and development in Latin America. Nueva York: Columbia University Press.

Trejo, S. (1973): Industrialización y empleo en México. México: Fondo de Cultura Económica.

Verdera, F. (1983): El empleo en el Perí: an nuevo enfoque. Lima: Instituto de Estudios Peruanos.

Wells, J. (1974): Distribution of earnings, growth and the structure of demand in Brazil during the 1960s. World dexelopment. Enero.

Wicht, J.J. (1983): El empleo en el Perú. Centro de Investigaciones de la Universidad del Pacifico. 